\title{
Response analysis of buried pipelines crossing fault due to overlying soil rupture*
}

\author{
Lei Zhao * Chengchen Cui and Xiaojun Li \\ Institute of Engineering Mechanics, China Earthquake Administration, Harbin 150080, China
}

\begin{abstract}
A 3-D soil-pipe nonlinear finite element model with contact element is suggested and the influences of the rupture mode, thickness and rigidity of overlying soil on the response of buried pipeline are analyzed. The numerical results show that the soil rupture mode determines the location of the large deformation or failure of the pipeline, and the plastic deformation of the pipeline occurs at the zone where the plastic deformation or rupture of the overlying soil appears. When the fault dip angle on bedrock is near $90^{\circ}$, two plastic deformation sections of the pipeline appear with the development of overlying soil rupture. And the thicker the overlying soil is, the longer the plastic deformation length of the pipeline is and the less its strain is. The plastic deformation length of the pipeline decreases while its maximum strain increases with the rigidity of overlying soil increasing.
\end{abstract}

Key words: fault; overlying soil; buried pipeline; finite element; contact element

CLC number: P315.9 Document code: A

\section{Introduction}

Buried pipelines crossing fault are often damaged in earthquakes due to forces and deformation imposed on them through interactions at the pipe-soil interface. That is, the ground moves and thereby causes the pipe to deform. Based on laboratory tests, some models of soilpipe interaction are established for the pipelines surrounded by non-liquefied soils. For example, Trautmann and O'Rourke (1983) established a force-deformation relation for horizontally lateral movement. Committee on Gas and Liquid Fuel Lifelines of the ASCE Technical Council on Lifeline Earthquake Engineering (1984) suggested an idealized elasto-plastic model, which is characterized by two parameters, namely, the maximum resistance and the maximum elastic deformation. In the model, the coefficient of the equivalent soil springs is simply taken as the ratio of the maximum resistance to a half of the maximum elastic deformation.

At the meantime, a number of investigations have been performed and analysis methods are proposed for consideration of tensile and bending behaviors of the pipeline due to strike-slip fault movement. The proposed

\footnotetext{
* Received 3 November 2009; accepted in revised form 4 January 2010; published 10 February 2010.

^ Corresponding author. e-mail: thunderlei 001@163.com

(c) The Seismological Society of China and Springer-Verlag Berlin Heidelberg 2010
}

methods include the Newmark-Hall approach (Newmark and Hall, 1975), the Kennedy approach (Kennedy et al, 1977), and the Wang-Yeh approach (Wang and Yeh, 1985). Newmark and Hall (1975) considered the model shown in Figure 1 with a total fault movement $\delta_{\mathrm{f}}$, in which a pipeline intersects a right lateral strike-slip fault at an angle $\beta$. For a pipe-fault intersection angle $\beta \leq 90^{\circ}$, the strike-slip fault results in tensile strain of the pipe. It is assumed that the pipeline is firmly attached to the soil at two anchor points. The bending stiffness of the pipeline as well as lateral interactions at the pipe-soil interface is neglected. Kennedy et al (1977) extended the ideas of Newmark and Hall, and incorporated the effects of lateral interaction for evaluating the maximum axial strain. Ariman and Lee (1991) evaluated pipe strain using the finite element method. The pipe is modeled as a thin cylindrical shell which is essentially semi-infinite (O'Rourke and Liu, 1999). Gan and Hou (1991) simulated response of pipeline crossing fault by a continuous foundation beam model. Liu (2002) simplified the boundary condition of shell finite element model by suggesting equivalent spring. All of these approaches mentioned above are mainly used to evaluate the pipe strain. Consideration of nonlinear property of the lateral soil spring and the pipe is the key problem in recent researches (Liu, 2002). 
Break of the continuous pipeline due to fault movement is the main damage phenomenon. For example, only a half of one percent of the area was affected by fault movement in the 1971 San Fernando earthquake, but the earthquake also resulted in over 1400 breaks in water, natural gas and sewer pipelines (McCaffrey and O'Rourke, 1983). Whether and where the pipe breaks appear needs to be paid high attention to in recent researches. The damage and breaks of pipeline are related to the rupture and large deformation of overlying soil due to bedrock fault dislocation, and the range of rupture and large deformation is determined by the thickness and the properties of soil, fault dislocation value, and fault dip angle (Zhao, 2004).
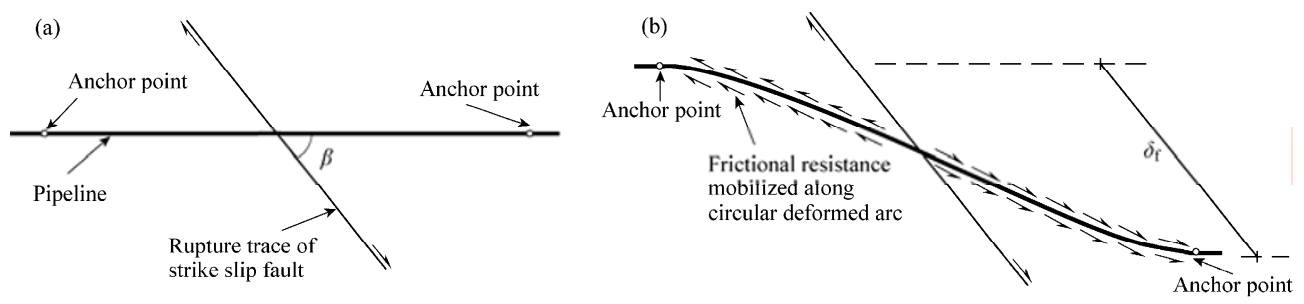

Figure 1 Analysis model in the Newmark-Hall approach where $\beta$ and $\delta_{\mathrm{f}}$ denote the fault dip angle and fault dislocation value, respectively. (a) Before fault movement; (b) After fault movement.

A 3-D soil-pipe nonlinear finite element model is established in this study to reveal the relation between the damage of the pipeline and the rupture of overlying soil. Response of the buried pipeline crossing fault and influences of the rupture mode, thickness and rigidity of the overlaying soil are studied.

\section{Methodology}

\subsection{FEM model}

Figure 2 is plane view of the analysis system and pipe-soil element finite model established in this study. ANSYS FEM program is used to do the numerical analysis of the pipe-soil element finite model. Longitudinal length of the model is $200 \mathrm{~m}$, thickness of the soil is considered as two cases: $23 \mathrm{~m}$ and $33 \mathrm{~m}$, the buried depth from the pipe axis $z$ to the soil surface is $3 \mathrm{~m}$, and the thickness of soil around the pipe in $x$ axis is $2 \mathrm{~m}$ from pipe axis to boundary of the model, where assum- ing that the constraint action of soil beyond this size is so weak that it can be ignored (Zhao, 2004). The soil is simulated by the solid element, and there are 200 elements in $z$ axis, 23 (or 33) elements in $y$ axis and four elements in $x$ axis. Diameter $D$ is $1 \mathrm{~m}$, and thickness $t$ of the pipe wall is $0.001 \mathrm{~m}$. The pipe is simulated by shell element, and there are eight elements in perimeter of pipe.

The pipeline moves together with the around soil in earthquake. At the soil-pipe interface, the rigidity of soil is far less than that of pipe, but movement of the soil and the pipe is of compatibility. The nonlinear state of the soil interface with action of contact and friction is called boundary nonlinearity. If this state is not considered, result of the FEM model is non-convergence. Therefore, CONTA 173 and TARGE 170 are used to simulate boundary nonlinearity. The interface of the soil element

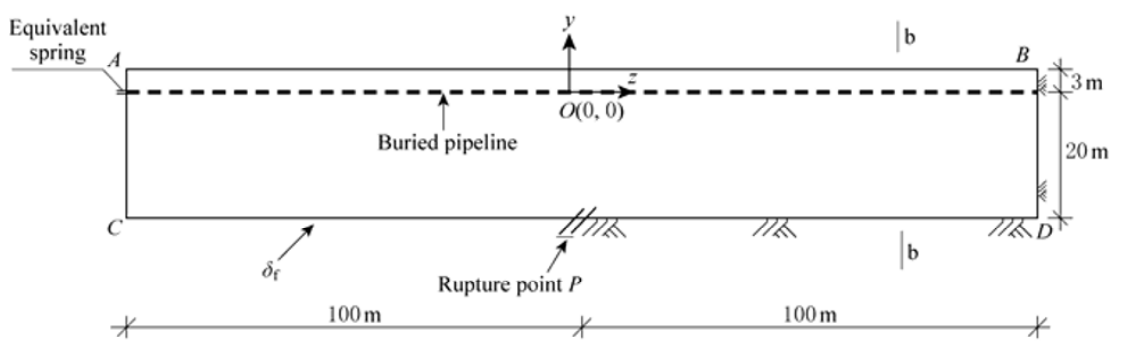

(a)

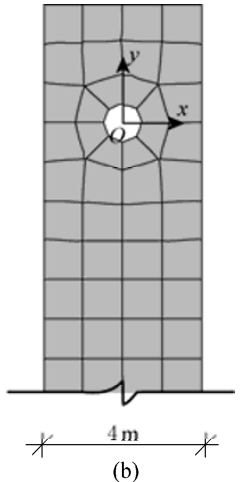

(b)

Figure 2 Plane view (a) and element finite model (b) of pipe-soil system. 
is attached to CONTA 173 element and that of the pipe element is attached to TARGE 170 element.

In the analysis system as shown in Figure 2, the left base line $C P$ is defined as an active-wall, the boundary $A C$ is free, but the left boundary of pipe is constrained by equivalent spring (Liu, 2002), and the boundary $B D$ is fixed. Pseudo-dynamic method is used, in which the bedrock fault movement is directly and slowly added in $y$ and $z$ directions on the active-wall, to analyze the response of the buried pipeline.

\subsection{Failure criterion}

The overlying soil is assumed as a homogeneous soil (clay or sand) in the soil-pipe model. Experimental studies have shown that the constitutive relation of soils can be expressed in hyperbola function:

$$
\tau=\frac{\gamma}{a+b \gamma}
$$

where $a$ and $b$ are parameters derived from soil tests, and are related to property of soil. And $a=1 / G_{\max }, b=1 / \tau_{\max }$, where $G_{\max }$ denotes the maximum shear modulus, i.e., $G_{\max }=\rho V_{\mathrm{S}}^{2}$, with $\rho, V_{\mathrm{S}}$ being the soil density and shear velocity respectively, and $\tau_{\max }$ denotes the maximum shear strength determined by Mohr-Column criterion.

Based on the identification rule of soil failure in engineering practice that if deformation of soil is up to $0.03-0.05 \mathrm{~m}$, the soil is considered failure, the deformation up to $0.03 \mathrm{~m}$ is considered as the failure value of soil in this study (Zhao et al, 2006).

Usually, Ramberg-Osgood model or tri-linear model is adopted to simulate the constitutive relation of the steel (pipe material in this study). When strain value of the pipe is not more than yield strain, Ramberg-Osgood model as stress-strain relationship of the steel pipe is better than tri-linear model. Ramberg-Osgood model can be expressed as

$$
\varepsilon=\frac{\sigma}{E}\left[1+\frac{n}{1+r}\left(\frac{|\sigma|}{\sigma_{y}}\right)^{r}\right],
$$

where $\varepsilon$ is strain, $\sigma$ is stress, $E$ is elastic modulus, $\sigma_{\mathrm{y}}$ is yield stress, $n$ and $r$ are parameters of Ramberg-Osgood model, here $n=10$ and $r=12$.

\section{Soil-pipeline model and response analysis}

In this study, the material of the pipe is X60 steel. In the physical parameters of the steel pipe, elastic modulus $E=2.1 \times 10^{11} \mathrm{~Pa}$, yield strain $\varepsilon_{\mathrm{y}}=0.002$, extreme strain $\varepsilon_{\max }=0.05$, Poisson ratio $v=0.3$. Physical parameters of the sand and clay are extracted from site condition investigation and earthquake safety evaluation of engineering projects, as shown in Table 1.

By changing fault dip angle and dislocation value of the bedrock fault, thickness and rigidity of the soil, earthquake responses are compared for four models of soil-pipeline systems. Detailed parameters of the models are given in Table 2. For a shell element, the ratio of length to width ought to be less than 2 to avoid being distorted, and the length of the element is $1 \mathrm{~m}$ in this study. For a solid element, the size is $1 \mathrm{~m} \times 1 \mathrm{~m} \times 1 \mathrm{~m}$. Thickness of the soil takes the value of $23 \mathrm{~m}$ or $33 \mathrm{~m}$ so that the rupture of fault can run through the whole overlying soil when vertical dislocation is up to $1.0 \mathrm{~m}$ or 1.5 $\mathrm{m}$ (Zhao, 2004). For influence of soil is our focus, material parameters and diameter $D$ of pipe are unvaried.

\begin{tabular}{|c|c|c|c|c|c|c|c|c|}
\hline & \multirow{2}{*}{$\begin{array}{l}\text { Density } \rho \\
\quad / \mathrm{kg}\end{array}$} & \multirow{2}{*}{$\begin{array}{l}\text { Velocity of shear } \\
\text { wave } V_{\mathrm{S}} / \mathrm{m} \cdot \mathrm{s}^{-1}\end{array}$} & \multirow{2}{*}{$\begin{array}{l}\text { Maximum shear } \\
\text { modulus } G_{\max } / 10^{8} \mathrm{~N} \cdot \mathrm{m}^{-2}\end{array}$} & \multirow{2}{*}{ Poisson ratio $v$} & \multicolumn{2}{|c|}{ Mohr-Column criterion } & \multirow{2}{*}{$\begin{array}{l}\text { Bearing stress } \\
\qquad / \mathrm{kPa}\end{array}$} & \multirow{2}{*}{$\begin{array}{l}\text { Maximum shear } \\
\text { stress } \Gamma_{\max } / \mathrm{Pa}\end{array}$} \\
\hline & & & & & Cohesion $/ \mathrm{kN}$ & Friction-angle ${ }^{\circ}$ & & \\
\hline Clay & 1940 & 220.6 & 0.944 & 0.3 & 43.5 & 18.5 & 240 & 123800 \\
\hline Sand & 2000 & 343.0 & 2.353 & 0.3 & 0 & 33.0 & 240 & 155858 \\
\hline
\end{tabular}

Table 1 Physical parameters of the soil

Table 2 Parameters of four models

\begin{tabular}{ccccc}
\hline No. of models & Sort of soil & Fault dip angle ${ }^{\circ}$ & Vertical dislocation $/ \mathrm{m}$ & 1.0 \\
Thickness of overlying soil $/ \mathrm{m}$ & 90 & 1.5 & 23 \\
2 & Clay & 90 & 1.0 & 33 \\
3 & Clay & 45 & 1.0 & 23 \\
4 & Clay & 90 & 23 \\
\hline
\end{tabular}

\subsection{Rupture mode of the overlying soil}

Figure 3 shows von Mises equivalent strain nephogram of the pipe for the responses of four models. The location of plastic deformation and the strain value are shown in Figures 4a, 4b, 4c and 4d for the models 1, 2, 3, and 4 , respectively. The results show that soil rupture 

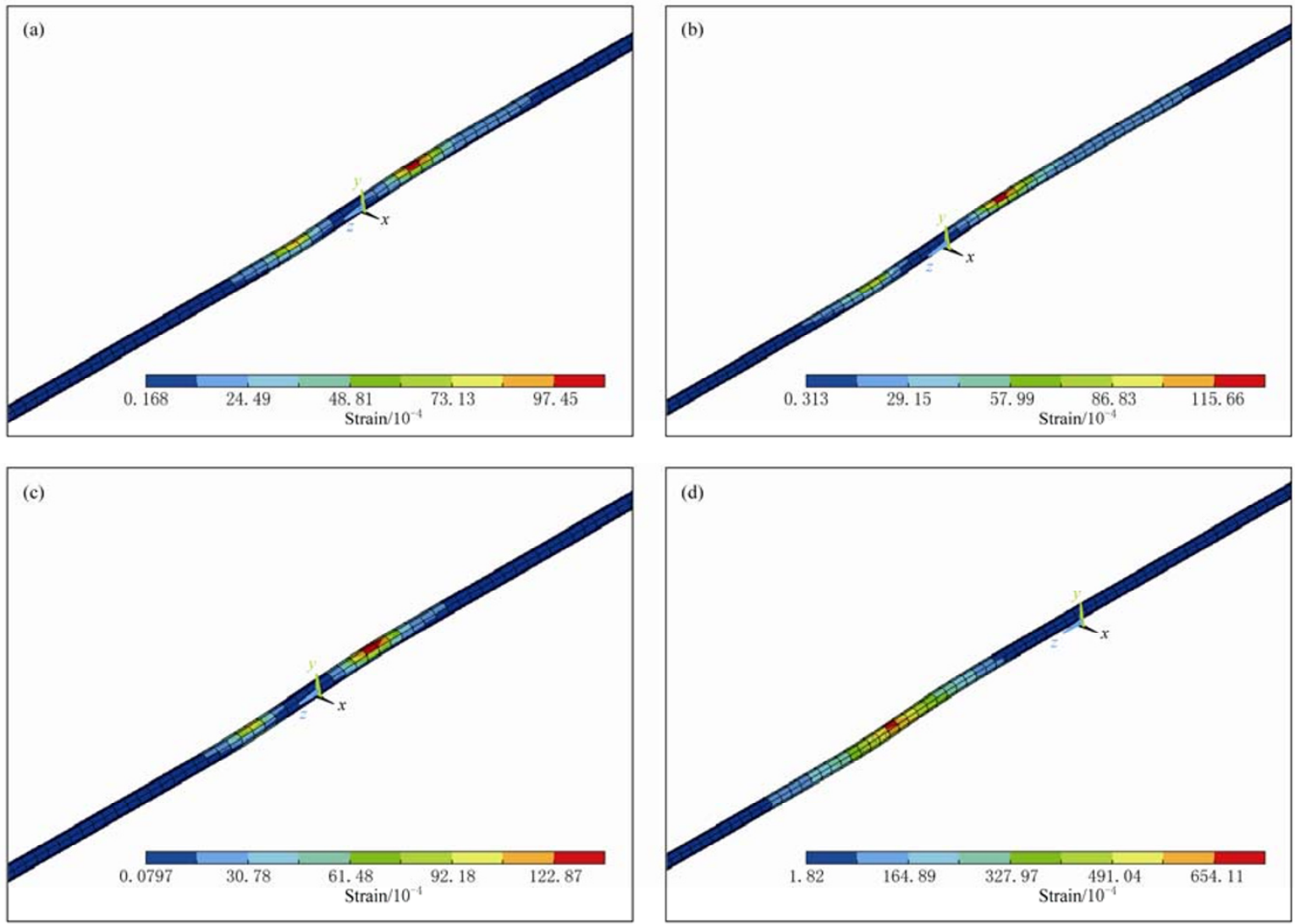

Figure 3 Von Mises equivalent strain of pipeline element for models 1 (a), 2 (b), 3 (c) and 4 (d)
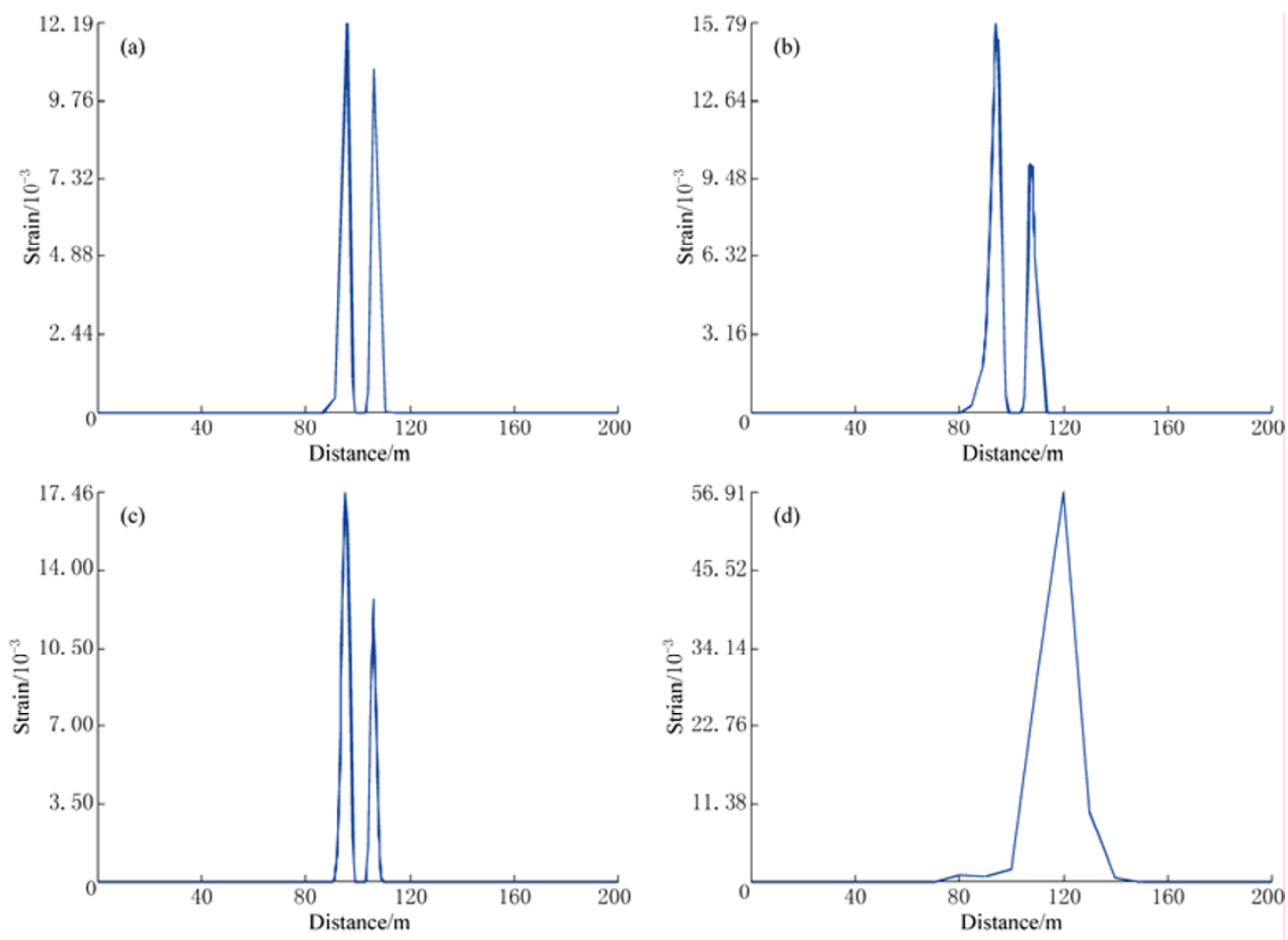

Figure 4 Plasticity strain location and its extreme at the buried pipeline for models 1 (a), 2 (b), 3 (c) and 4 (d). 
mode determines the locations where the pipeline undergoes large deformation or failure, and plastic deformation of the pipeline occurs in the pipeline section that runs through the zone where the plastic deformation or rupture of the overlying soil occurs.

Owing to difference in the fault dip angle, two kinds of rupture modes appear in the overlying soil. The first mode is that, when the fault dip angle is larger, close to 90 degree, the rupture trace through the soil is like the letter "Y"; the second one is that, when the fault dip angle is not so large such as 45 degree, the rupture trace is an inclined line (Zhao and Li, 2004; Li et al, 2009). Corresponding to the rupture modes of the soil, two kinds of deformation modes of pipeline also appear. When the fault dip angle is closer to $90^{\circ}$, two sections of plastic deformation appear at the intersection between the pipe and the rupture trace "Y" of soil (Figures 3a, 3b, $3 c)$. When the fault dip angle is not so large such as 45 degree, only one section of plastic deformation appears.

\subsection{Thickness of soil}

In the case of fixed dislocation value and dip angle of the fault, with thickness of the overlying soil becoming thicker, plastic deformation length of the buried pipeline increases, while the maximum strain decreases. The results for the model 2 demonstrate that when the dislocation value is $1.0 \mathrm{~m}$, the maximum strain is 0.011 16 , and lengths of the two plastic sections are $20 \mathrm{~m}$ and $15 \mathrm{~m}$. However, if the thickness of the overlying soil is $23 \mathrm{~m}$ but not $33 \mathrm{~m}$ for the model 2, the maximum strain is 0.01219 , and the lengths are $17 \mathrm{~m}$ and $20 \mathrm{~m}$ (Figure $3 b)$. The thicker the overlying soil is, the stronger deformation capability of soil is. Strain of pipe is related to the pipe-soil interaction. When the plastic deformation of soil appears, the plastic deformation also appears in the pipe section running through the soil, and its strain value is also determined by strain value of soil.

\subsection{Rigidity of soil}

In this paper, the velocity of shear wave (in unit of $\mathrm{m} / \mathrm{s})$ of soil is in the range of $(140,500]$. Rigidity of soil affects rupture angle of the overlying soil. When the rigidity is higher (S-velocity is larger), the rupture angle is larger and the rupture area is narrower comparatively. When the rigidity is low (S-velocity is slow), the angle is smaller and the area is wide. Intersection points of rupture trace of the soil and pipe are the positions of extreme strain of the pipe.

Plastic deformation length of the pipeline buried in the hard soil is short, while its maximum strain is high. In this study, rigidity of the sand is larger than that of clay. The results of the pipe response in clay are shown in Figures $3 \mathrm{a}$ and $4 \mathrm{a}$, and those in sand are shown in Figures $3 \mathrm{c}$ and $4 \mathrm{c}$. Figure $4 \mathrm{a}$ shows that the plastic deformation length of the pipe buried in clay is $17 \mathrm{~m}$ and $10 \mathrm{~m}$, and the maximum strain is 0.01219 . Figure $4 \mathrm{c}$ shows that the plastic deformation length of the pipe buried in sand is only $11 \mathrm{~m}$ and $8 \mathrm{~m}$, but the maximum strain is 0.01746 .

\section{Discussion and conclusions}

The finite element model with contact elements is established to analyze the response of buried pipeline due to bedrock fault dislocation by consideration of pipe-soil nonlinear interaction in this study. The results in this study demonstrate that properties of overlying soil on bedrock have great effects on response of the buried pipeline crossing the earthquake fault. The rigidity and thickness of soil are the main factors to affect the large deformation length of the pipeline. Plastic deformation locations of the buried pipe are affected by the rupture or deformation mode of the overlying soil, and the extreme strain section of pipe follows the trace of the rupture and large deformation of overlying soil on bedrock. Therefore, when the buried pipe crosses the rupture zone of the overlying soil, the failure of pipe may exist, which will be paid attention to in practice engineering.

The study reveals some phenomena of the response of buried pipeline due to earthquake fault and their formation mechanism. It is also found that the nonlinear finite element method should be adopted to make detail analysis on the response of buried pipeline instead of the simplified methods such as the Newmark-Hall approach and the Kennedy approach.

In this study, vertical dislocation value of bedrock fault is constrained by the size of the element, because the deformation of element at the abrupt point is distorted, which results in invalidation of element when the vertical dislocation is oversize. This will be considered in future study.

Acknowledgments This study is supported by the National Natural Science Foundation of China (50778166), the Basic Research Fund of State Level Research Institutes, Institute of Engineering Mechanics of China Earthquake Administration (2007B09) and the National Scientific and Technological Support Project from Ministry of Science and Technology (2006BAC13B02). 


\section{References}

Ariman T and Lee B J (1991). Tension/Bending behavior of buried pipelines under large ground deformation in active faults. Proceedings of the third U.S. Conference on Lifeline Earthquake Engineering. Technical Council on Lifeline Earthquake Engineering, ASCE, New York, (4): 226-233.

Committee on Gas and Liquid Fuel Lifelines of the ASCE Technical Council on Lifeline Earthquake Engineering (1984). Guidelines for the Seismic Design of Oil and Gas Pipeline Systems. ASCE, New York, 10-12.

Gan S W and Hou Z L (1991). Aseismic of Buried Pipe. Seismological Press, Beijing, 49-93 (in Chinese).

Kennedy R P, Chow A W and William R A (1977). Fault movement effects on buried oil pipeline. J Transp Eng, ASCE 103: 617-633.

Li X J, Zhao L and Li Y Q (2009). Simulation of earthquake fault induced rupture process of soil layers on bedrock. Chinese J Rock Mecha Eng 28(Suppl. 1): 2 703-2 707 (in Chinese with English Abstract)

Liu A W (2002). Response Analysis of a Buried Pipeline Crossing the Fault Based on Shell-model. PhD Dissertation, Institute of Geophysics, China Earthquake Administration, Beijing, 41-45 (in Chinese with English abstract).

O'Rourke M J and Liu X (1999). Response of Buried Pipelines Subject to Earthquake Effects. Multidisciplinary Center for Earthquake Engineering Research, New York, 77-155.
McCaffrey M A and O'Rourke T D (1983). Buried pipeline response to reverse faulting during the 1971 San Fernando earthquake. In: Earthquake Behavior and Safety of Oil and Gas Storage Facilities, Buried Pipelines and Equipment, PVP-77. ASME, New York, June 1983, 151-159.

Newmark N M and Hall W J (1975). Pipeline design to resist large fault displacement. Proc. U.S. National Conference on Earthquake Engineering. Ann Arbor, Michigan, 416-425.

Trautmann C H and O'Rourke T D (1983). Load-displacement characteristics of a buried pipe affected by permanent earthquake ground movements. In: Earthquake Behavior and Safety of Oil and Gas Storage Facilities, Buried Pipelines and Equipment, PVP-77. ASME, New York, June 1983, 254-262.

Wang L R L and Yeh Y H (1985). A refined seismic analysis and design of buried pipeline for fault movement. Earthq Eng Struct Dynam 13(1): $75-96$.

Zhao L (2004). Study on Rupture Process of Overlaying Soil due to Fault Bedrock Dislocation of Earthquake Fault and Its Effects on Buried Pipelines. PhD Dissertation, Institute of Geophysics, China Earthquake Administration, Beijing, 21-58 (in Chinese with English abstract).

Zhao L, Li X J and Huo D (2006). Study on the rupture characteristics of the overlaying soil with soft interlayer due to fault dislocation. Acta Seismologica Sinica 19(5): 563-568. 